\title{
KOMPARASI MODEL PREDIKSI BEBAN PUNCAK HARIAN LISTRIKANTARA ALGORITMA BACKPROPAGATION DENGAN ALGORITMA KOHONEN MAP
}

\author{
Sandy Bhawana Mulia \\ Program Studi Teknik Elektro Politeknik Enjinering Indorama \\ Jl. Kembang Kuning, Jatiluhur - Purwakarta \\ e-mail : sandybhawana@gmail.com
}

\begin{abstract}
Abstrak : Teknologi Soft Computing telah membantu banyak peneliti dalam mengembangkan sebuah penelitiannya. Contohnya adalah pengembangan model prediksi beban listrik harian non linier berbasis kecerdasan buatan yang menggunakan algoritma Backporpagation dan algoritma Kohonen Map. Kode computer yang dikembangkan menggunakan software Matlab R2008b dari Mathwork Corp. Dapat dilihat dari hasil perhitungan bahwa keakuratan model Backpropagation 99,83 \% sedangkan model Kohonen Map hanya 97,53\%. Dengan demikian dapat disimpulkan bahwa model prediksi menggunakan algoritma Backpropagation lebih baik tingkat akurasinya dibandingkan dengan model prediksi menggunakan metoda Kohonen Map.
\end{abstract}

Kata Kunci : Algoritma Backpropagation, Algoritma Kohonen Map, Prediksi Beban Listrik

\begin{abstract}
Soft Computing technology has helped many researchers to develop a research. An example is the development of daily electrical load forecasting nonlinear artificial intelligence model based Backporpagation algorithms and Kohonen Map algorithms. Computer code which has been developed using Matlab R2008b Software of Mathwork Corp. It can be seen from the calculation that the accuracy of the Backpropagation model is $99.83 \%$, while Kohonen Map model is just $97.53 \%$. It can be concluded that the model forecasting using Backpropagation algorithms accuracy is better than model forecasting using Kohonen Map method.
\end{abstract}

Keywords: Backpropagation algorithm, Kohonen Map algorithm, Electric Load Forecasting

\section{Pendahuluan}

Di era globalisasi ini Indonesia yang tergolong negara berkembang sedang giatgiatnya melaksanakan pembangunan di segala bidang sehingga meningkatkan permintaan daya listrik. Untuk mempertahankan unjuk kerja sistem tenaga listrik maka sistem harus terus dikembangkan. Dimana secara teortitis daya yang dibangkitkan harus selalu sama dengan daya yang dikonsumsi oleh para pemakai tenaga listrik yang secara teknis umumnya dikatakan sebagai beban sistem.

Tapi kenyataanya beban sistem berubah-ubah sepanjang waktu tergantung kepada 
keperluan para pemakai tenaga listrik. Dengan tidak adanya rumus eksak yang dapat memastikan besarnya beban untuk setiap saat, maka yang dapat dilakukan adalah hanya memprediksi. Di lain pihak perkembangan teknologi soft computing akhirnya menghasilkan metoda alternatif prediksi beban puncak harian listrik jangka pendek berbasis jaringan syaraf tiruan (Artificial Neural Network). Dengan pemanfaatan teknologi soft computing tersebut dapat dengan mudah memprediksi kebutuhan beban listrik per hari, bulan, dan tahun.

Pada makalah ini akan dipaparkan metode prediksi beban puncak harian listrik berbasis jaringan syaraf tiruan dengan algoritma Backpropagation dan Kohonen Map.

\section{Landasan Teori}

\subsection{Algoritma Backpropagation}

Backpropagation merupakan algoritma pembelajaran yang terawasi (supervised) dan biasanya digunakan oleh perceptron dengan banyak lapisan untuk mengubah bobot-bobot yang terhubung dengan neuron-neuron yang ada pada lapisan tersembunyinya.

Algoritma backpropagation menggunakan error output untuk mengubah nilai bobot-bobotnya dalam arah mundur (backward). Untuk mendapatkan error ini, tahap perambatan maju (forward propagation) harus dikerjakan dulu. Pada saat perambatan maju, neuron-neuron diaktifkan dengan menggunakan fungsi aktivasi yang dapat dideferensialkan seperti fungsi sigmoid.

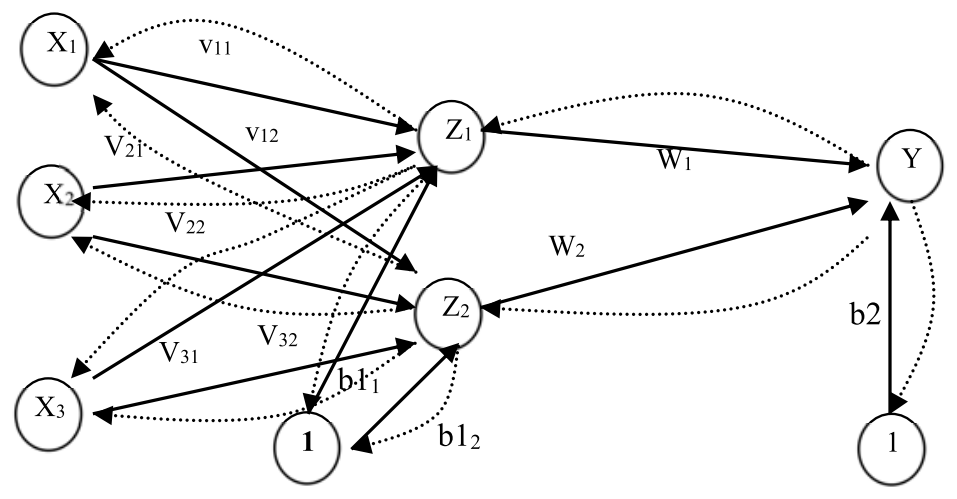

Gambar 1 Arsitektur Jaringan Backpropagation

Arsitektur jaringan backpropagation seperti ditunjukan pada gambar 1 terdiri atas 3 unit neuron pada lapisan input, yaitu $\mathrm{x}_{1}, \mathrm{x}_{2}$, dan $\mathrm{x}_{3} ; 1$ lapisan tersembunyi dengan 2 neuron, yaitu $\mathrm{z}_{1}$ dan $\mathrm{z}_{2}$; serta 1 unit pada lapisan output yaitu $\mathrm{y}$. Bobot yang menghubungkan $\mathrm{x}_{1}, \mathrm{x}_{2}$, dan $\mathrm{x}_{3}$ dengan neuron pertama pada lapisan tersembunyi adalah $\mathrm{v}_{11}, \mathrm{v}_{21}$, dan $\mathrm{v}_{31}$ ( $\mathrm{vij}$ : bobot yang menghubungkan neuron input ke-i ke neuron ke-j pada lapisan tersembunyi), $b_{11}$ dan $b_{12}$ adalah bobot bias yang menuju ke neuron pertama dan kedua pada lapisan tersembunyi. Bobot yang menghubungkan $\mathrm{z}_{1}$ dan $\mathrm{z}_{2}$, dengan neuron pada lapisan output adalah $\mathrm{w}_{1}$ dan $\mathrm{w}_{2}$. Bobot bias $\mathrm{b}_{2}$ menghubungkan lapisan 
tersembunyi dengan lapisan output. Fungsi aktivasi yang digunakan adalah logsig.

Algoritma backpropagation dikerjakan dengan langkah-langkah sebagai berikut:

1. Inisialisasi bobot (ambil bobot awal dengan nilai random yang cukup kecil).

2. Tetapkan: Maksimum epoh, target error, dan learning rate $(\alpha)$.

3. Inisialisasi: $\mathrm{Epoh}=0, \mathrm{MSE}=1$.

4. Kerjakan langkah-langkah berikut selama (Epoh $<$ maksimum Epoh) dan MSE $>$ target error):

a. Feedforward

b. Backpropagation

5. Hitung MSE (Mean Squared Error).

\subsection{Kohonen Map}

Kohonen map merupakan salah satu algoritma jaringan syaraf tiruan terbaik, metoda ini cukup unik karena membangun sebuah topology preserving map dari ruang berdimensi tinggi ke dalam neuron-neuron sebagai representasi dari datapoint-datapoint yang ada.

Kohonen map merupakan salah satu metoda jaringan syaraf tiruan unsupervised (tidak terawasi), jaringan ini tidak mendapatkan target, sehingga jaringan syaraf tiruan mengatur bobot interkoneksi sendiri. Belajar tanpa pengawasan kadang-kadang diacu sebagai Self Organizing Learning, yakni belajar mengklasifikasikan tanpa dilatih. Pada proses belajar tanpa pengawasan, jaringan syaraf tiruan akan mengklasifikasikan contoh pola-pola masukan yang tersedia ke dalam kelompok yang berbeda-beda. Ketika data diberikan ke dalam jaringan syaraf, data akan mengatur struktur dirinya sendiri untuk merefleksikan dari pola yang diberikan. Pada kebanyakan model ini, batasan mengacu pada determinasi kekuatan antar neuron.

\section{Topologi Jaringan Kohonen Map}

Dalam jaringan kohonen, neuron target tidak diletakan dalam sebuah baris, tetapi neuron target diletakan dalam 2 dimensi yang topologinya dapat diatur. Untuk mendefinisikan topologi jaringan terdapat 3 macam topologi yang dapat dibuat yaitu gridtop, hextop, dan randtop.

1. Gridtop (Grid Topology)

Topologi dengan posisi neuron membentuk pola menyerupai segi empat. Ditentukan dengan membuat koordinat neuron dalam $n$ baris dan $n$ kolom. 


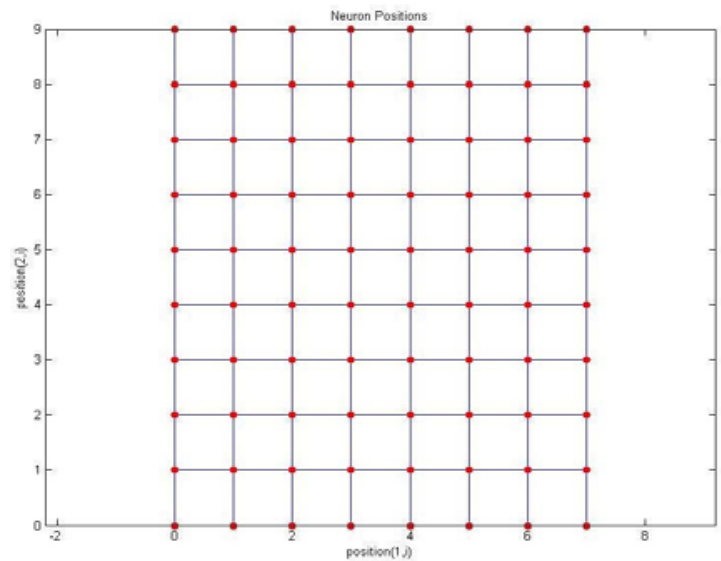

Gambar 2 Grid Topology

2. Hextop (Hexagonal Topology)

Topologi dengan posisi neuron membentuk pola menyerupai segi enam. Ditentukan dengan membuat koordinat neuron dalam $n$ baris dan $n$ kolom.

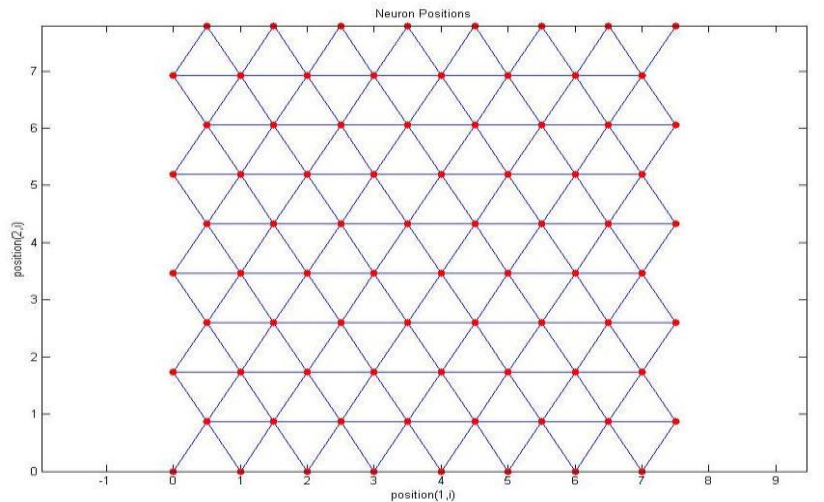

Gambar 3 Hexagonal Topology

3. Randtop (Random Topology)

Topologi dengan posisi neuron membentuk pola secara acak. Ditentukan dengan membuat koordinat neuron dalam $\mathrm{n}$ baris dan $\mathrm{n}$ kolom.

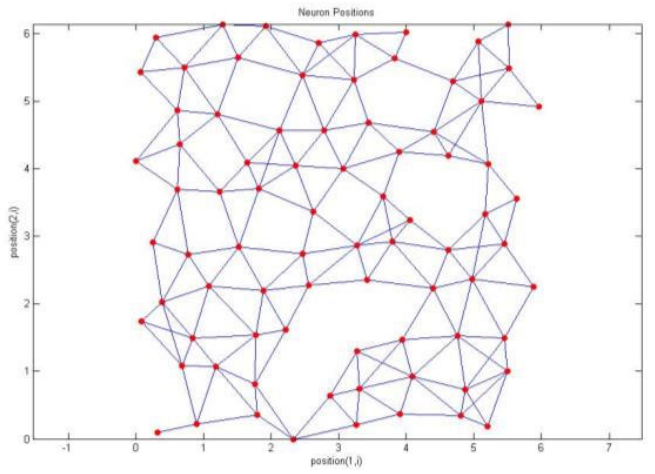

Gambar 4 Random Topology 


\section{Hasil Dan Pembahasan}

Sumber data yang akan dianalisis adalah data pengeluaran beban puncak listrik dari Pusat Pembagi Beban (P3B) PT. PLN (Persero) Jawa Bali Region Barat pada pukul $17.00 \mathrm{~s} / \mathrm{d} 22.00$ mulai hari senin sampai hari minggu sebanyak 4 minggu. Perangkat lunak pendukung untuk merancang program digunakan MATLAB ver. R2008b dari The MathWorks, Inc.

Perbandingan hasil prediksi model Backpropagation dan model Kohonen Map dapat dilihat pada gambar 5 sampai 11 di bawah ini yang memperlihatkan profil beban puncak harian listrik pada hari senin sampai minggu, dimana ada perbedaan pola yang agak mencolok di hari jum'at sampai minggu. Hal ini dikarenakan industri ataupun perkantoran saat menjelang weekend mulai berkurang aktivitasnya, sehingga pola pemakaian listrik antara hari jum'at sampai minggu memiliki perbedaan yang cukup signifikan.

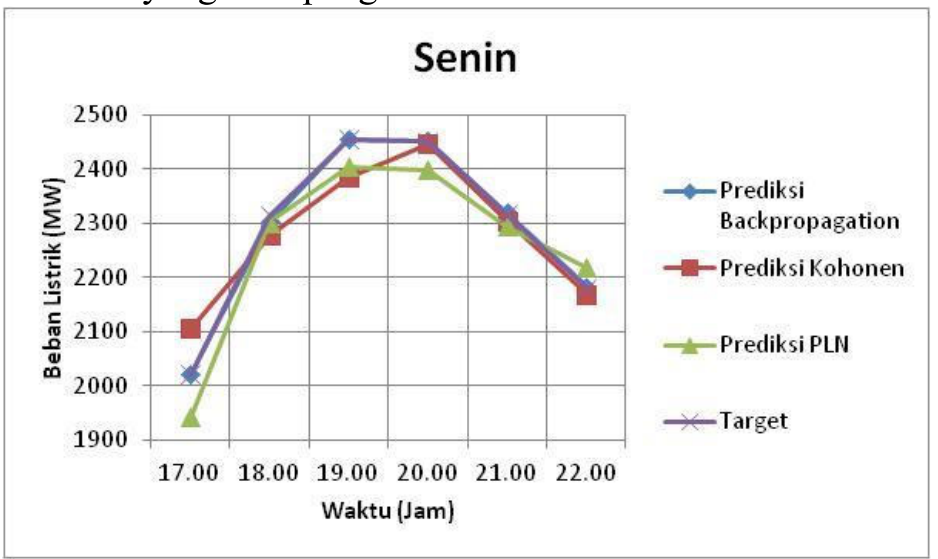

Gambar 5 Perbandingan Hasil Prediksi untuk Hari Senin

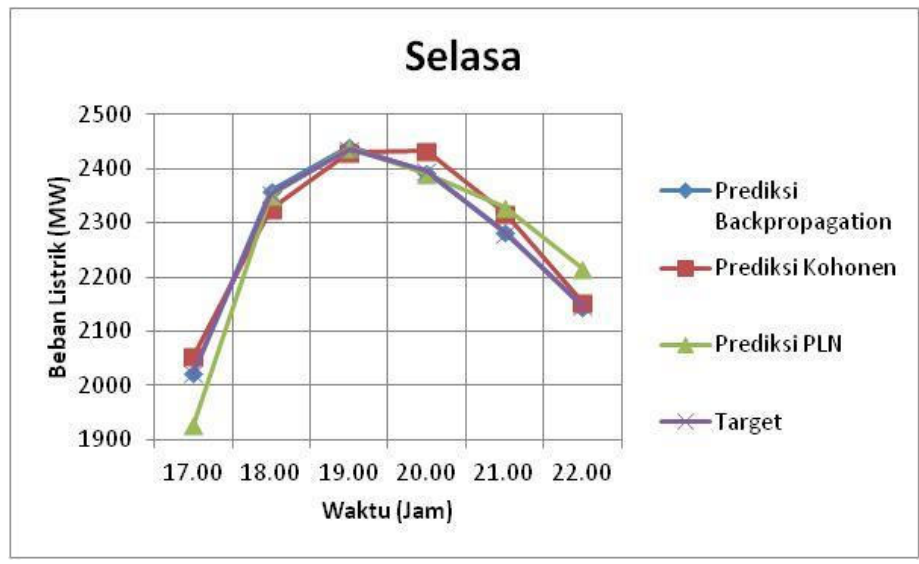

Gambar 6 Perbandingan Hasil Prediksi untuk Hari Selasa 


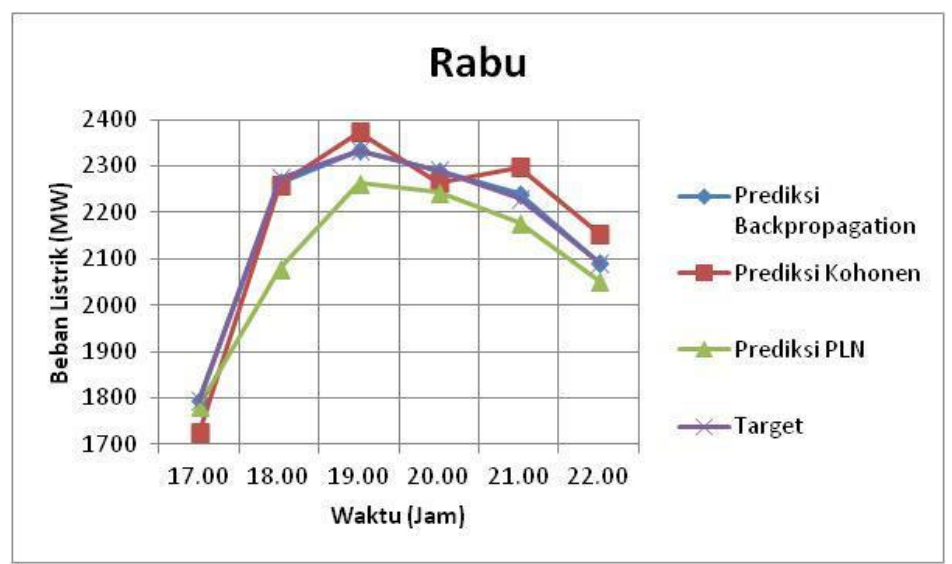

Gambar 7 Perbandingan Hasil Prediksi untuk Hari Rabu

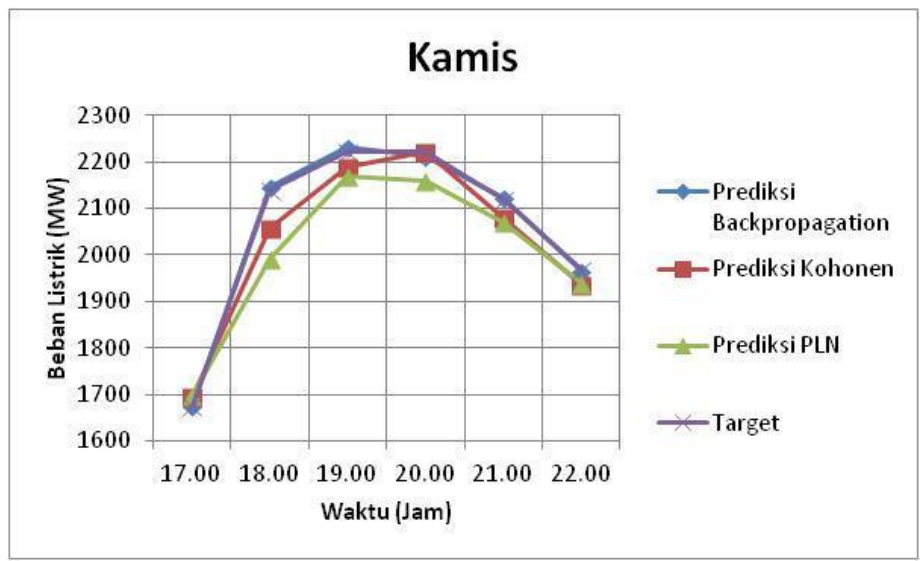

Gambar 8 Perbandingan Hasil Prediksi untuk Hari Kamis

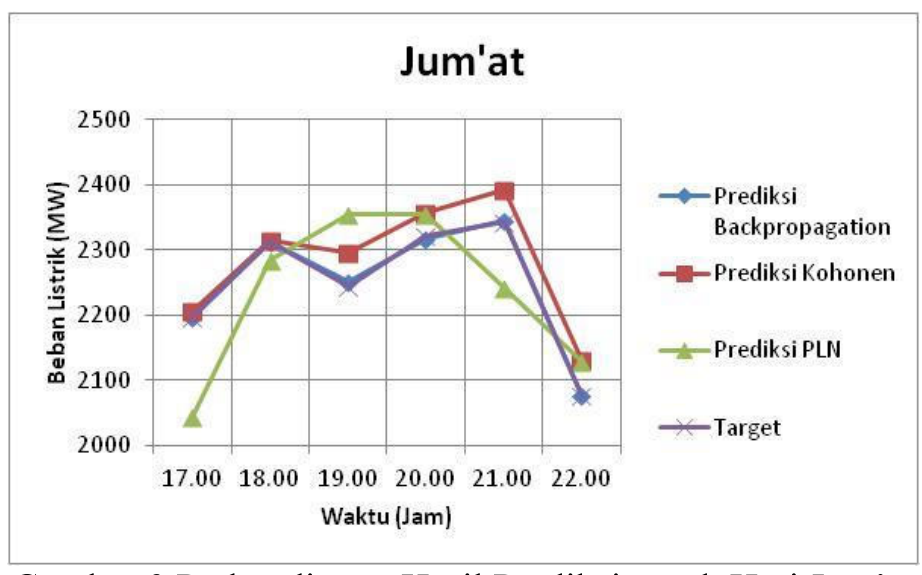

Gambar 9 Perbandingan Hasil Prediksi untuk Hari Jum'at 


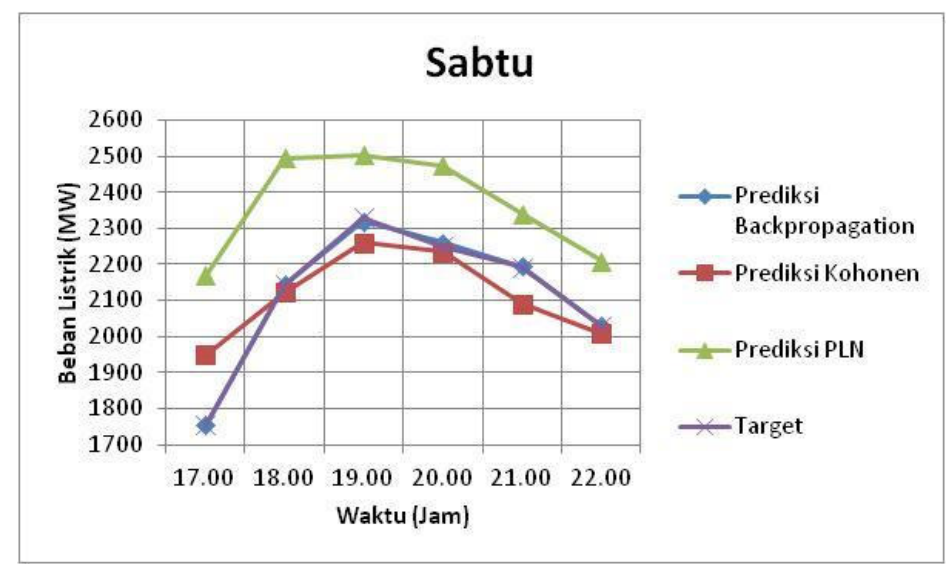

Gambar 10 Perbandingan Hasil Prediksi untuk Hari Sabtu

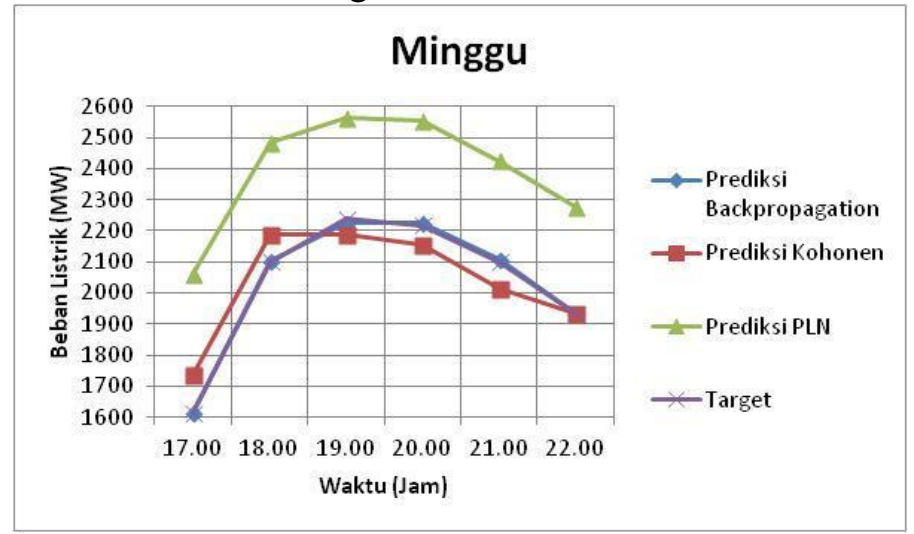

Gambar 11 Perbandingan Hasil Prediksi untuk Hari Minggu

Hasil prediksi di atas ternyata memberikan error prediksi yang signifikan untuk model prediksi Kohonen Map daripada Backprogation (lihat gambar 12). Hal ini memberikan bukti bahwa model prediksi Backpropagation lebih unggul dibandingkan dengan model prediksi Kohonen Map, karena sesuai dengan karakteristik algoritmanya yang tersupervisi.

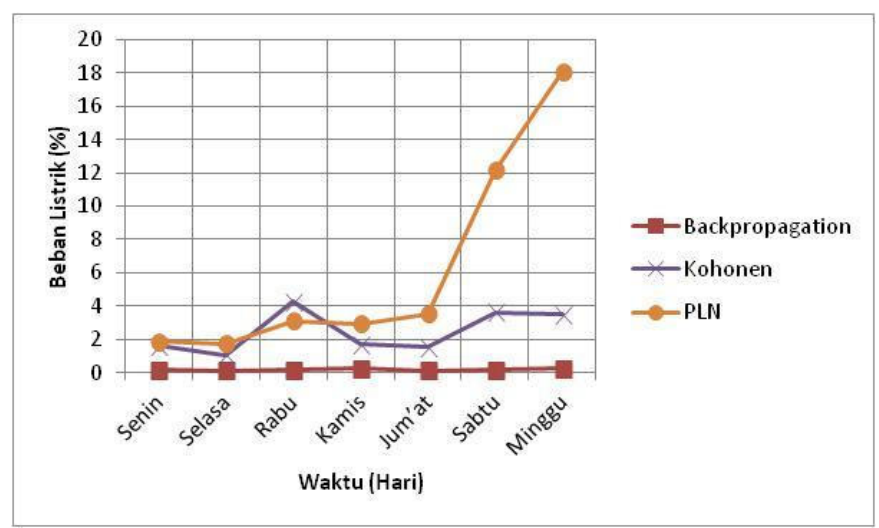

Gambar 12 Grafik Perbandingan Rata - Rata Error Model Backpropagation dan Kohonen Map 
Selain itu, dapat dilihat bahwa hasil simulasi dan perhitungan yang telah dilakukan memberikan beberapa informasi, seperti:

1. Prediksi beban puncak harian dengan metoda Kohonen map menghasilkan rata - rata error secara keseluruhan sebesar 2,47\%, prosentase rata - rata error Kohonen map terbesar pada hari Rabu yaitu 4,26\%, sedangkan rata rata error Kohonen map terkecil pada hari Selasa yaitu 1,06\%.

2. Prediksi beban puncak harian dengan metoda Backpropagation menghasilkan rata-rata error secara keseluruhan sebesar $0,169 \%$, prosentase rata - rata error Backpropagation terbesar pada hari Kamis yaitu 0,247 \%, sedangkan rata - rata error Backpropagation terkecil pada hari Jum'at yaitu $0,098 \%$.

3. Dengan perbandingan rata - rata dari Hari Senin sampai Minggu adalah 0,169 \% untuk Backpropagation, dan 2,47 \% untuk Kohonen map, maka tampak jelas bahwa Backpropagation mempunyai kemampuan yang lebih baik dalam memprediksikan beban puncak harian listrik dibandingkan dengan Kohonen map. Hasil rata - rata error sebesar 0,169 \% ini sebenarnya masih belum maksimal, artinya masih memungkinkan untuk menghasilkan yang lebih baik. Karena pada penelitian ini hanya menggunakan data-data numerik saja dari beban - beban masa lalu, tanpa memperhitungkan faktorfaktor eksternal seperti pengaruh keadaan cuaca, curah hujan, pertumbuhan ekonomi, keadaan politik negara, dan faktor - faktor lainnya yang dapat memperngaruhi prediksi. Selain itu faktor internal yang dapat mempengaruhi hasil prediksi diantaranya penentuan hidden layer, penentuan jumlah neuron, penentuan rating rate, dan penentuan epoch. Oleh karena itu dengan melakukan beberapa alternatif terhadap variabel-variabel di atas memungkinkan dapat memperoleh hasil yang lebih baik.

\section{Kesimpulan}

Berdasarkan hasil dari uraian di atas terlihat bahwa model prediksi Backporopagation mempunyai kemampuan lebih baik dalam dibandingkan model prediksi Kohonen Map. Selain itu, dapat diambil beberapa kesimpulan, bahwa:

1. Dalam memprediksikan beban listrik jangka pendek selain metode yang telah ada (metoda konvensional yang dipakai oleh PLN), ternyata dapat pula digunakan model prakiran dengan menggunakan Jaringan Syaraf Tiruan (JST) khususnya algoritma Backpropagation yang memberikan hasil yang cukup baik.

2. Hasil prediksi beban puncak harian listrik dengan menggunakan algoritma Backpropagation dengan algoritma Kohohnen Map telah diperoleh, dimana prediksi dengan mengunakan algoritma Backpropagation lebih mendekati data aktualnya dibandingkan dengan algoritma Kohohnen Map.

3. Melalui perhitungan secara statistik didapatkan rata-rata error keseluruhan untuk kedua metode, yaitu 0,169 \% untuk Backpropagation dan 2,47 \% untuk Kohonen Map. Hanya ingin membandingkan saja bahwa hasil prediksi menggunakan metoda konvensional (metoda koefisien beban) yang dipakai oleh PLN memiliki rata-rata error sebesar 6,21\%. Dengan demikian dapat 
disimpulkan bahwa prediksi beban listrik jangka pendek dengan menggunakan algoritma Backpropagation tingkat akurasinya lebih baik dibandingkan dengan algoritma Kohonen Map maupun metoda koefisien beban yang dilakukan oleh PLN.

\section{Daftar Pustaka}

[1] Abdia, Gunaidi. (2006). The Shorcut Of MATLAB Programing. Bandung: Informatika.

[2] Gaffar. Ade. (2005). Perencanaan dan Pembuatan Perangkat Lunak Untuk Prediksi Beban Listrik Harian Berbasis Logika Fuzzy. Bandung: Universitas Pendidikan Indonesia.

[3] Kakkonda. Tetsuya. Electric Load Forecasting by Neural Networks Considering Various Load Types. Japan: Member IEEE Intelligent System Applications to Power System (ISAP 2003).

[4] Kher. V. H. Short - Term Electrical Load Forecasting Using ANN. India: University Of Baroda.

[5] Kuswadi, Son. (2007). Kendali Cerdas. Yogyakarta: ANDI Yogyakarta.

[6] Mandal. J. K. Application of Recurrent Neural Network for Short Therm Load Forecasting in Electrical Power System. India: India Institute of Technology.

[7] Marsudi, Djiteng. (1990). Operasi Sistem Tenaga Listrik. Jakarta: Balai Penerbit \& HUMAS ISTN.

[8] Mulyadi, Yadi. Estimasi Beban Puncak Harian Berbasis Algoritma Self Organizing Map (SOM). Bandung: Universitas Pendidikan Indonesia.

[9] Nurhayati, Wina. (2007). Model Prakiraan Beban Listrik Jangka Pendek Menggunakan Aplikasi ANFIS. Bandung: Universitas Pendidikan Indonesia.

[10] Nurjaman, Risman. (2009). Pengembangan Model Estimasi Beban Puncak Harian Menggunakan Algoritma Kohonen Map. Bandung: Universitas Pendidikan Indonesia.

[11] Ortiz. Daniel. Accurate Electricity Load Forecasting with ANN. Denmark: University Esbjerg Denmark.

[12] Sharif. Saied. S. Short - Term Load Forecasting by Feed - Forward Neural Network. Canada: University Of New Brunswick.

[13] Siang, Jong Jek. (2004). Jaringan Syaraf Tiruan dan Pemogramannya dengan MATLAB, Yogyakarta: Andi.

[14] Solihudin, Oih. (2005). Prakiraan Beban Listrik Jangka Pendek Menggunakan Jaringan Syaraf Tiruan. Bandung: Universitas Pendidikan Indonesia.

[15] Tsoukalas. L. H. A New Load Forecasting Methodology. Indiana USA: Purdue University. 
[16] Vesanto. Juha. (1999). Self-Organizing Map in Matlab: The SOM Toolbox. Finland: Helsinki University Of Technology. 